Corrigendum

\title{
Corrigendum to "The Value of Safflower Yellow Injection for the Treatment of Acute Cerebral Infarction: A Randomized Controlled Trial”
}

\author{
Le-Jun Li, ${ }^{1,2}$ Yu-Mei Li, ${ }^{1}$ Ben-Yu Qiao, ${ }^{1}$ Shan Jiang, ${ }^{1}$ Xin Li, ${ }^{1}$ \\ Hong-Ming $\mathrm{Du},{ }^{3}$ and Peng-Cheng Han ${ }^{2}$ \\ ${ }^{1}$ Department of Neurology, Affiliated Lianyungang Hospital of Nanjing University of Chinese Medicine, \\ No. 160 W. Chaoyang Road, Lianyungang 222000, China \\ ${ }^{2}$ Barrow Neurological Institute, St. Joseph's Hospital and Medical Center, Phoenix, AZ 85013, USA \\ ${ }^{3}$ Changchun Sanzhen Industry Co., Ltd., Changchun 130000, China
}

Correspondence should be addressed to Yu-Mei Li; lygzyyliyumei@hotmail.com

Received 20 July 2016; Accepted 10 August 2016

Copyright (C) 2016 Le-Jun Li et al. This is an open access article distributed under the Creative Commons Attribution License, which permits unrestricted use, distribution, and reproduction in any medium, provided the original work is properly cited.

In the article titled "The Value of Safflower Yellow Injection for the Treatment of Acute Cerebral Infarction: A Randomized Controlled Trial" [1], Dr. Jiong Shi was incorrectly included as an author. The corrected author list is shown above.

\section{References}

[1] L.-J. Li, Y.-M. Li, B.-Y. Qiao et al., "The value of Safflower Yellow Injection for the treatment of acute cerebral infarction: a randomized controlled trial," Evidence-Based Complementary and Alternative Medicine, vol. 2015, Article ID 478793, 6 pages, 2015. 


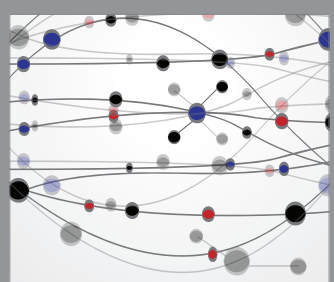

The Scientific World Journal
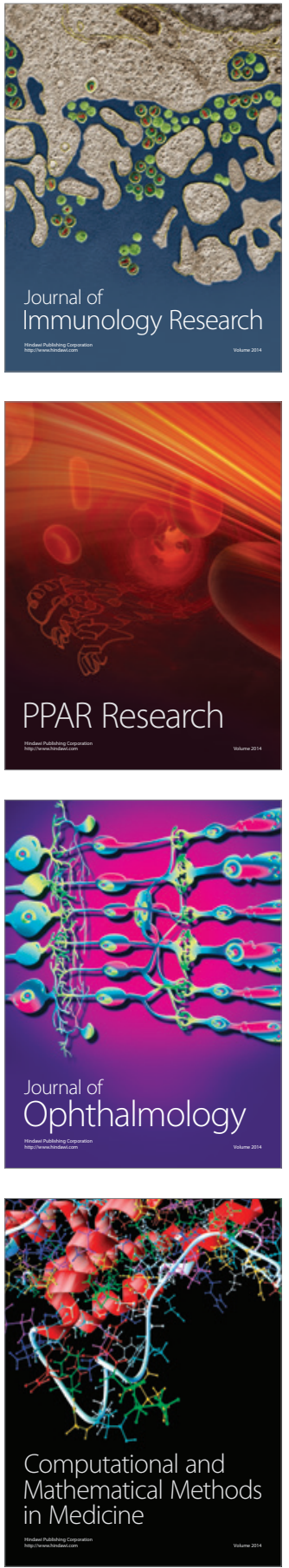

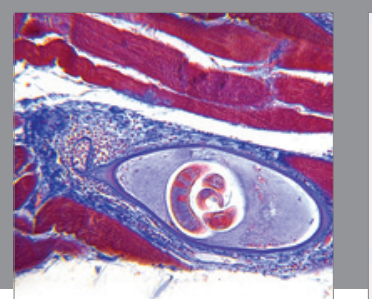

Gastroenterology Research and Practice

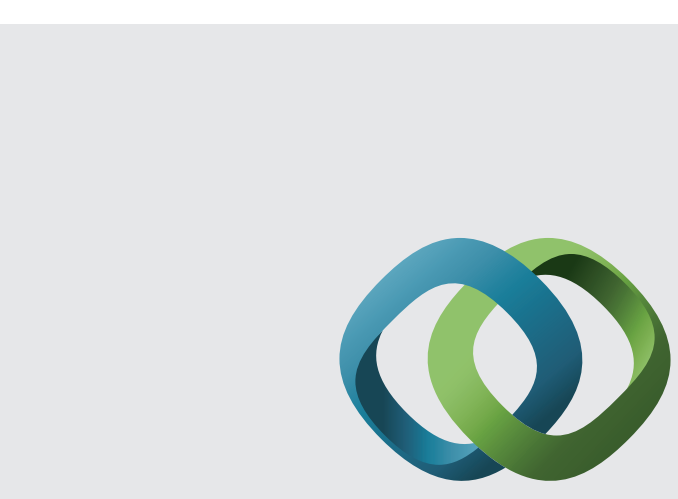

\section{Hindawi}

Submit your manuscripts at

http://www.hindawi.com
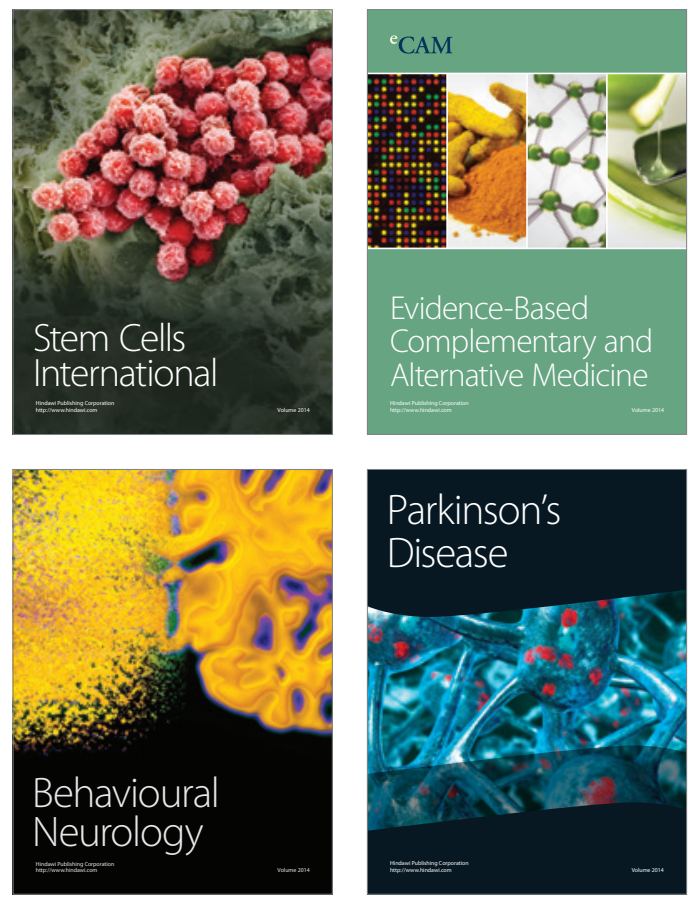
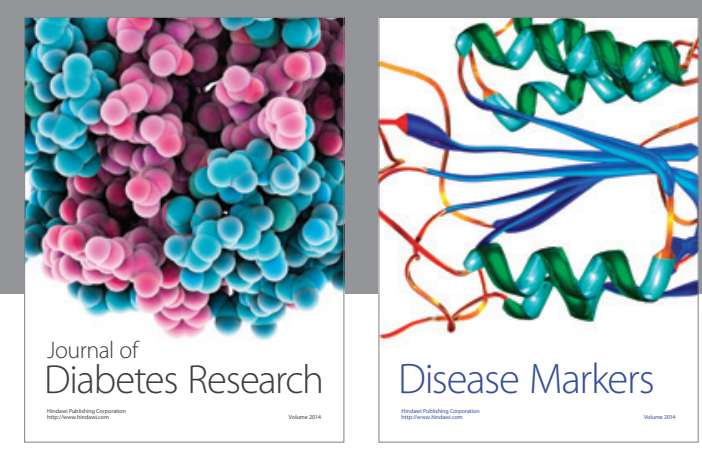

Disease Markers
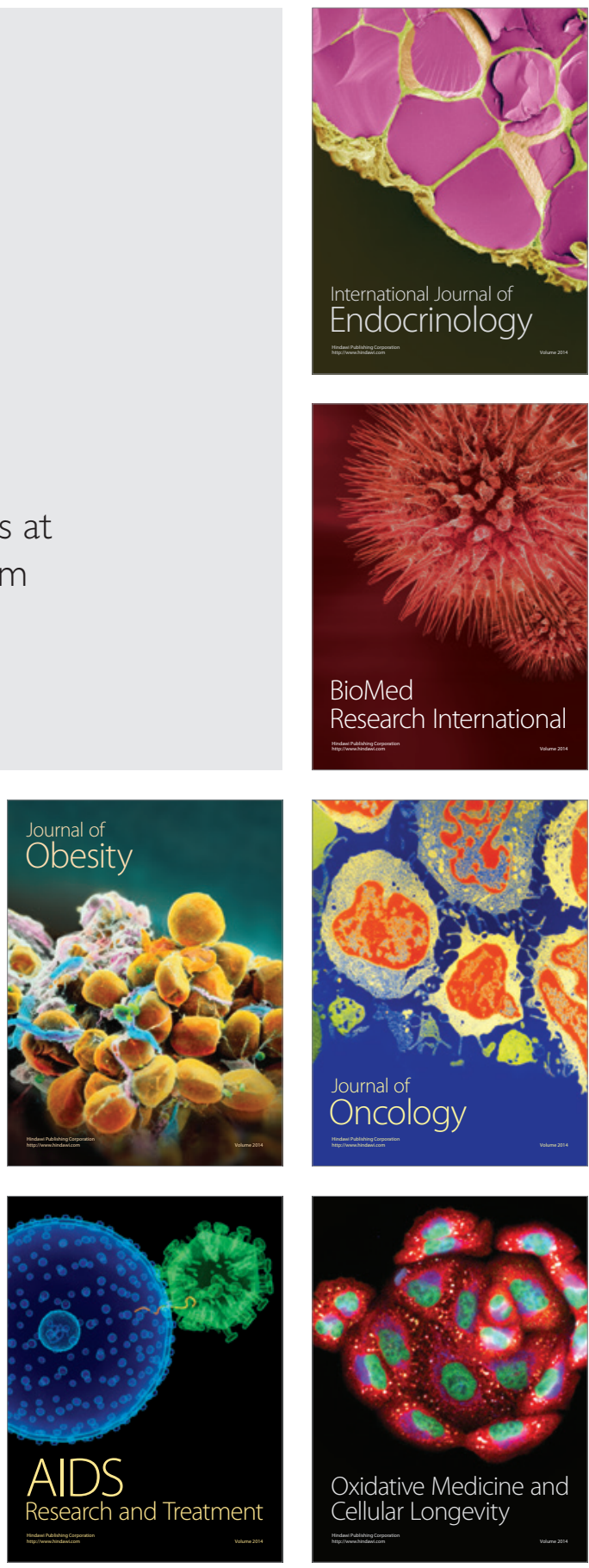